\title{
Crazy, but correct
}

\section{How a non-conformist theory beat scepticism and got into the textbooks.}

\section{Daniel E. Koshland Jr}

$\mathrm{T}$ he event that marked the biggest change in my career was the postulation of a controversial theory at a fairly early stage of my working life. In the late 1950s, I was working as an assistant professor at Brookhaven National Laboratory, New York. I was studying the muscle enzyme hexokinase, and was puzzled as to why water - an analogue of glucose, the enzyme's natural substrate, and present at a much higher concentration - did not react with hexokinase. I began to think about the role of water in general and realized that the major obstacle of a living system was not so much the need to 'activate' water to react when needed, as the need to prevent water from reacting in cases where it was not needed to do so. It then dawned on me that any mechanism for hexokinase activity based on Emil Fisher's long-established 'lock and key' theory (sometimes called the 'key-lock' or 'template' theory) for enzyme-substrate interactions would result in catastrophic losses to side reactions in real life. Moreover, the logic behind this realization about water would also apply to other cases where a smaller analogue of the true substrate failed to react with an enzyme.

I went back over my thoughts and experiments. Finding no errors, I decided that the template theory needed revision. Instead of the wooden jigsaw-puzzle analogy of fitting for the template model, my concept was more like the fit of a hand in a glove, a moderately flexible enzyme (the glove) fitting a moderately flexible substrate (the hand). I felt this was the better analogy for proteins and substrates. Speaking very simplistically, in the 'induced-fit' model, water could not substitute for the larger glucose to induce a conformational change in the enzyme, allowing it to react. Whereas in the template model, all the catalytic groups are already aligned so that water could react. In addition, my theory explained so many previously unexplained phenomena that I felt it had to be right.

Realizing that a young scientist was largely identified as promising on the basis of one or two good papers - and could be largely destroyed on the basis of one or two bad papers - I was aware of the risks I was taking. But I had become so enamoured of what I called the 'induced-fit' theory that I decided to publish it.

I remember giving a talk about it at a meeting of the American Chemical Society. As I walked out of the hall, I heard a couple of young scientists say, "Koshland used to do

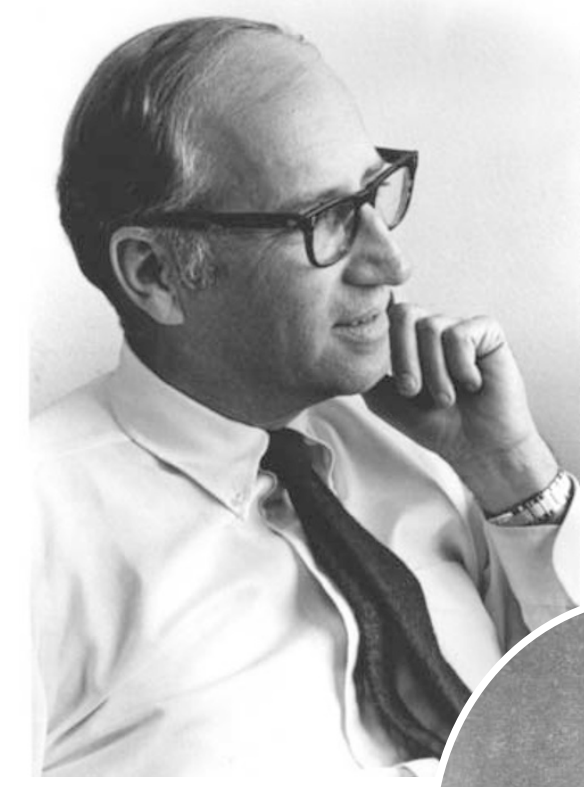

Now, many years later when the theory is explained in textbooks of biochemistry, it is enlightening to look back and learn from the progression of a theory from unconventional hypothesis to conventional wisdom.

I remember my angry reaction and frustration at the journals that rejected my articles. I realize now that a new theory is likely to meet resistance, but it should, if based on good experiments, receive sceptical encouragement if science is to remain in balance. Non-conformists are necessary for progress in science, just as mutations are necessary for progress in evolution. However, there must be constraints to select good mutations from bad mutations. Too many mutations block evolution, as error-prone strains of bacteria have proved.

So non-conformist thinking in science must be encouraged to make progress, but restrained to prevent anarchy. In science, it is peerreviewed journals and granting agencies that provide such balance.

The trouble is that good work, but he seems to have gotten senile prematurely." After an invited lecture in Gatlinburg, Tennessee, the applause was polite, but tepid. I asked fellow enzymologist, Ron Breslow, what he thought of the audience reaction. He said, "Dan, if you should turn out to be right, at least you can say that no one in that room believed you at the time."

Some journals were skeptical and rejected my manuscripts with statements such as, "The theory of Emil Fischer has been a cornerstone for 100 years and will not be overturned by the ideas of an obscure young biochemist from a young national laboratory." However, other journals did agree to publish my work, so the theory became part of scientific discourse and I received many invitations to talk about it.

The theory also explained many other enzymatic phenomena - such as hormone action, feedback inhibition, cooperativity and receptor function - so its acceptance grew slowly, but steadily. Its progress was accelerated a few years later when X-ray crystallography (initially carried out in the laboratories of Thomas Steitz and William Lipscomb) revealed pictures of enzymesubstrate interactions in carboxypeptidase and hexokinase occuring exactly as predicted by the induced-fit theory. The success of the theory emboldened me, an organic chemist, to venture into new biological areas, such as sensory signalling, which I would not have dared to enter before. journals can easily become too conservative, because editors find it easier to reject the unusual than to take a chance on the unthinkable. Later in life, when I became editor-in-chief of the journal Science, my early experience allowed me to keep a friendly eye out for the non-conformist. But it is not easy to select between the unexpected and the impossible in today's world of increasing specialization and exponential increase in knowledge. The existence of multiple journals provides the final safeguard against too much conservatism and is the ultimate reason that science is more receptive to non-conformity than any other segment of our society. But does science have any lessons for non-conformism in other spheres, such as politics and religion?

Non-conformity is looked on with more hostility by religion, government and culture than by science - because each of them is more vulnerable to change than science is. The other segments of our society have yet to find a better mechanism for encouraging non-conformity to achieve progress, while still controlling non-conformity to prevent chaos. Science has achieved the best balance, but it must fight to preserve this and serve as a beacon to other sectors of our society.

Daniel E. Koshland is in the Department of

Molecular and Cell Biology, University of

California, Berkeley, California 94720, USA. 